\title{
Epidemiological Pattern of Trauma Among the Children in Southwestern Iran from 2012 to 2016
}

\author{
${ }^{1}$ Zahra Gorjian, ${ }^{2}$ Mina Baghbani, ${ }^{3}$ Diba Nikkhah Dashtizadeh, ${ }^{4}$ Atefeh Zahedi, ${ }^{5}$ Rana Hamedpour \\ ${ }^{1}$ Faculty Member of Nursing Department, Abadan School of Medical Sciences, Abadan, Iran, ${ }^{2,3}$ Student of \\ Operating Room, Student Research Committee, Abadan school of Medical Sciences, Abadan, Iran, \\ ${ }^{4}$ Abadan School of Medical Sciences, Abadan, Iran, ${ }^{5}$ Nursing Student Research Committee, Abadan school \\ of Medical Sciences, Abadan, Iran \\ *Email:M.Baghbani@yahoo.com
}

\section{Received: $08^{\text {th }}$ December 2017, Accepted: 26 $^{\text {th }}$ December 2017, Published: $2^{\text {th }}$ February 2018}

\begin{abstract}
Introduction: Since trauma is a threatening factor against the human beings, 10000 people are annually killed in the accident. 10 percent of those incidents belong to children. The aim of this study is to examine the epidemiologic trauma pattern among the children ranging in age from 1 to 15 years old. Methodology: This study was a cross-sectional research which dealt with ex-post facto analysis and it was conducted through examine the census of accidents among 1994 files of children with trauma. The sample was between 1 to 15 years old they referred to ER since they had accidents that caused trauma. Their personal data like gender, age, types of trauma and the place of incidents were recorded. Then the anatomy of trauma and the death toll of the incidents were registered through the checklist. The collected data were calculated through SPSS, version.21 and the descriptive (i.e., frequency, percentage, tables and figures) and inferential (i.e., Chi-square and spearman) statistics. Results: Finding showed that among 1994 cases of trauma, there were 65.7 percent males and 43.3 percent female cases. Most trauma incidents were happened in the streets or home and the least ones were at schools. The highest frequency of happenings was car accident and falling down. The most anatomic place of body was the multiple trauma and limbs. The most frequent trauma was seen in the head and neck and the least one was recorded in the chest. Among all the patients, 98.1 percent were discharged in the hospital and 1.9 percent died. Conclusion: Since can accident and falling down were the most frequent incidents causing trauma and the places like streets and houses were frequent, training the parents on how to be careful in providing the children with safe cars and secure environments can decrease trauma in children.
\end{abstract}

Keywords: Children, Epidemiology, Mortality, Trauma

\section{Introduction}

Trauma is a kind of damage which directly and indirectly affects the baby in an intentional or unintentional modes. This may include traffic, toxic, falling down, drawing traumas (Amani, 2009).
Trauma goes back to the history of human beings from the past to the present and it causes the damage or death of many children and young people in developed and industrial countries (Zargar, 2002). Nowadays, trauma is one of the problems in the medical practice and it causes many social and financial problems (Kiakejori, 2012). The problems of trauma in the society threaten the health of people in that society (Rahmani, 2013). It is the most epidemic cause of death among the people between the age ranges of 1 to 44 . It is also in the third rank of causes of death without considering the causes of death (Arhamidolatabadi, 2016; Davoodabadi, 2011). Truman is one of the causes of losing the potential time of life in developing countries regarding the death of the young people (Ramooz, 2014). In Iran, trauma is in the second rank of death after cardiovascular diseases (Hassanzadeh, 2015). It is estimated that there are 1.5 million people who die annually because of trauma and millions of people should be hospitalized in a long period of time (Haghinejad, 2015). In the US, there are 160000 deaths and 50000 people are disabled due to the causes of trauma (Yaghobi, 2010; Amani, 2009). The examining of trauma which causes death in every 100000 people in the world has shown that there are 99 people in the world and 58 people in Iran (Zamani, 2014). According to World Health Organization (WHO), the death toll will be reaching to 40 percent up to 2030 (Noroozinia, 2016). According to WHO, there are 78 million people who need medical care regarding the problems of trauma. Seven percent of all deaths refer to this matter in the world.

Among the trauma victims, children are the frequent ones (Souri, 2002). In other words, children are very susceptible to trauma making death (Abdoli, 2014). Children are big part of the population in the country and they are the victims of this happening which causes them to refer to the ER. Moreover, trauma is the causes of their death or disability between the age of 1 to 14 (Arhamidolatabadi, 2016; Avarello, 2007; Meamarzade, 2011). Trauma is the cause of more than 10000 deaths and 10 present of hospitalized children in the world (Cooper, 1993; Meamarzade, 
2011). The identification of trauma and the happening in order to prevent and control of its damages is important (Bijani, 2013). Since providing the causes of trauma can help study of trauma in our country, the examining of trauma incidents may prevent these happenings (Agran, 1998; Arhamidolatabadi, 2016; Forouzanfar, 2014; Javid, 2006; Safari, 2014). Thus the present study examined the epidemic pattern of trauma in the children who referred to Abadan and Khoramshar hospitals from 2011 to 2017 in Iran.

\section{Methodology}

The present study is a cross-sectional descriptive research which follows the ex-post facto method and it aimed at investigating the epidemic trauma among the children under 15 years old in Abadan and Khoramshahr cities at the hospitals of Talleghani, Shahid Beheshti and Valiasr from 2011 to 2017 in Iran.

The method of statistical census was used to collect data and all the children who were under 15 years old and refer to the hospitals regarding trauma were recorded. After receiving the permission of recording the patients' information and demographic data concerned with the place of trauma, the season of the medical operation were recorded in a researcher-made checklist. The data were collected through the medical cases of the hospitals HIS (Hospital information system). The cases which are incomplete or unclear were deleted.

The trauma mechanism was classified into five categories including car accident, falling down, burning, drowning and being toxic. The places of anatomical baby parts were classified into the categories of head and neck, Jaws and face, spinal cord, abdomen, limbs, chest, etc. The trauma condition refer to the patients' condition which causes death or discharge the hospital. Finally, 1994 cases were recorded and analyzed through SPSS, version 21 regarding descriptive (i.e., mean, frequency, charts and figures) and inferential (i.e., Chi-square and Spearman) statistics.

\section{Results}

This study was conducted based on the census method through an ex-post facto research. 1994 cases of children under 15 years old, who were hospitalized in ER, were recorded and analyzed. The results showed that 65.7 percent of children were males and 34.3 percent of the children were females. The highest frequency belonged to the age of 5 years old and the least one belong to the age of 1.5 years old. The variables like the place of trauma, the body organ, the season and the type of cases were recorded in terms of the patients' gender. The results are presented in Table1.

Table 1. Frequency of the Patients with Trauma based on their Gender

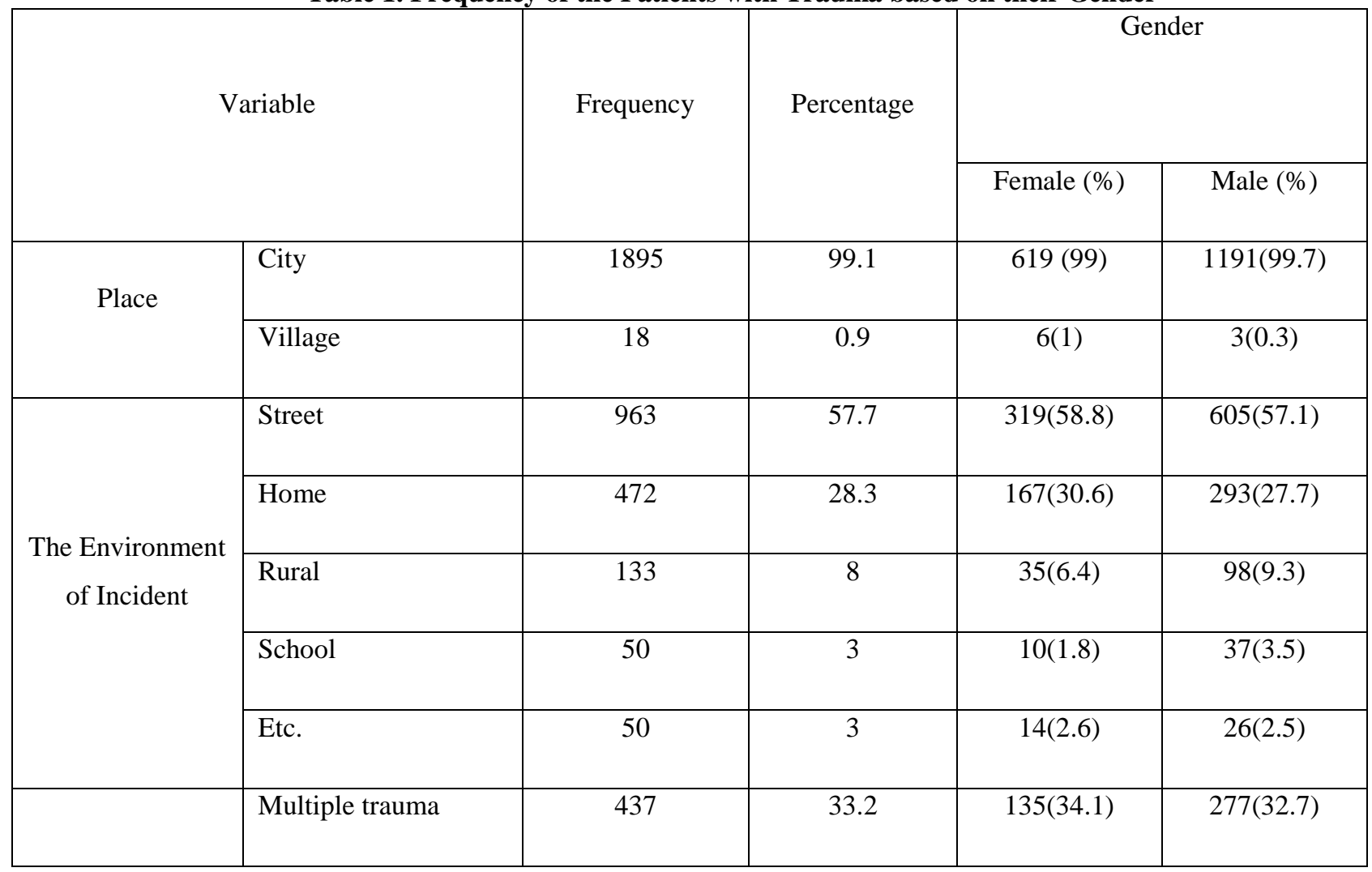


Helix Vol. 8(2): 3224-3228

\begin{tabular}{|c|c|c|c|c|c|}
\hline \multirow{7}{*}{$\begin{array}{c}\text { Body Damage } \\
\text { (Trauma) }\end{array}$} & limbs & 395 & 30 & $107(27)$ & 251(29.6) \\
\hline & Head \& neck & 360 & 27.4 & $117(29.5)$ & $235(27.7)$ \\
\hline & Jaws \& face & 55 & 4.2 & $15(3.8)$ & $38(4.5)$ \\
\hline & abdomen & 30 & 2.3 & $9(2.3)$ & $21(2.5)$ \\
\hline & Spinal cord & 21 & 1.6 & $9(2.3)$ & $11(1.3)$ \\
\hline & Chest & 6 & 0.5 & $1(0.3)$ & $5(0.6)$ \\
\hline & Etc. & 6 & 0.5 & $3(0.8)$ & $9(1.1)$ \\
\hline \multirow{2}{*}{ Death } & No & 1761 & 98.1 & $560(98.4)$ & $1110(97.9)$ \\
\hline & Yes & 34 & 1.9 & $9(1.6)$ & $24(2.1)$ \\
\hline \multirow{4}{*}{ Season } & Spring & 513 & 26.9 & $187(30.1)$ & $323(27.1)$ \\
\hline & Autumn & 493 & 25.9 & $143(23)$ & $330(27.7)$ \\
\hline & Winter & 453 & 23.8 & $146(23.5)$ & $238(20)$ \\
\hline & Summer & 447 & 23.5 & $146(23.5)$ & $299(25.1)$ \\
\hline \multirow{7}{*}{$\begin{array}{c}\text { The Type of } \\
\text { Accident }\end{array}$} & Car accident & 1179 & 63.7 & $374(62)$ & $731(63.3)$ \\
\hline & Falling down & 519 & 28 & $154(25.5)$ & $348(30.1)$ \\
\hline & Medical toxic & 77 & 4.2 & $39(6.5)$ & $37(3.2)$ \\
\hline & burning & 64 & 3.5 & $32(5.3)$ & $32(2.8)$ \\
\hline & Detergent toxic & 5 & 0.3 & $2(0.3)$ & $2(0.2)$ \\
\hline & Cycling & 4 & 0.2 & $0(0)$ & $4(0.3)$ \\
\hline & Drawing & 3 & 0.2 & $2(0.3)$ & $1(0.1)$ \\
\hline
\end{tabular}

Table 1 shows that there are 99.1 percent of the cities in which trauma has happened and the rest belongs to the villages. The frequent trauma accidents happens in the streets with 57.7 percent and the least. The highest frequency of trauma is seen at schools and other places with 0.3 percent. The most frequent boby parts trauma is seen at multiple trauma with 33.2 percent, limbs with 30 percent, trauma of the head and neck with 27.4 percent and the least on belongs to chest with 0.5 percent.

The highest and lowest percentage of trauma was in spring $(26.9 \%)$ and in summer $(23.5 \%)$ respectively. Moreover, the most mechanism of causing trauma is car accident $(63.7 \%)$, falling down $(28 \%)$ and the least incidents were drawing (0.2) and cycling (0.2). 
Figure 1 shows the classification of trauma based on gender.

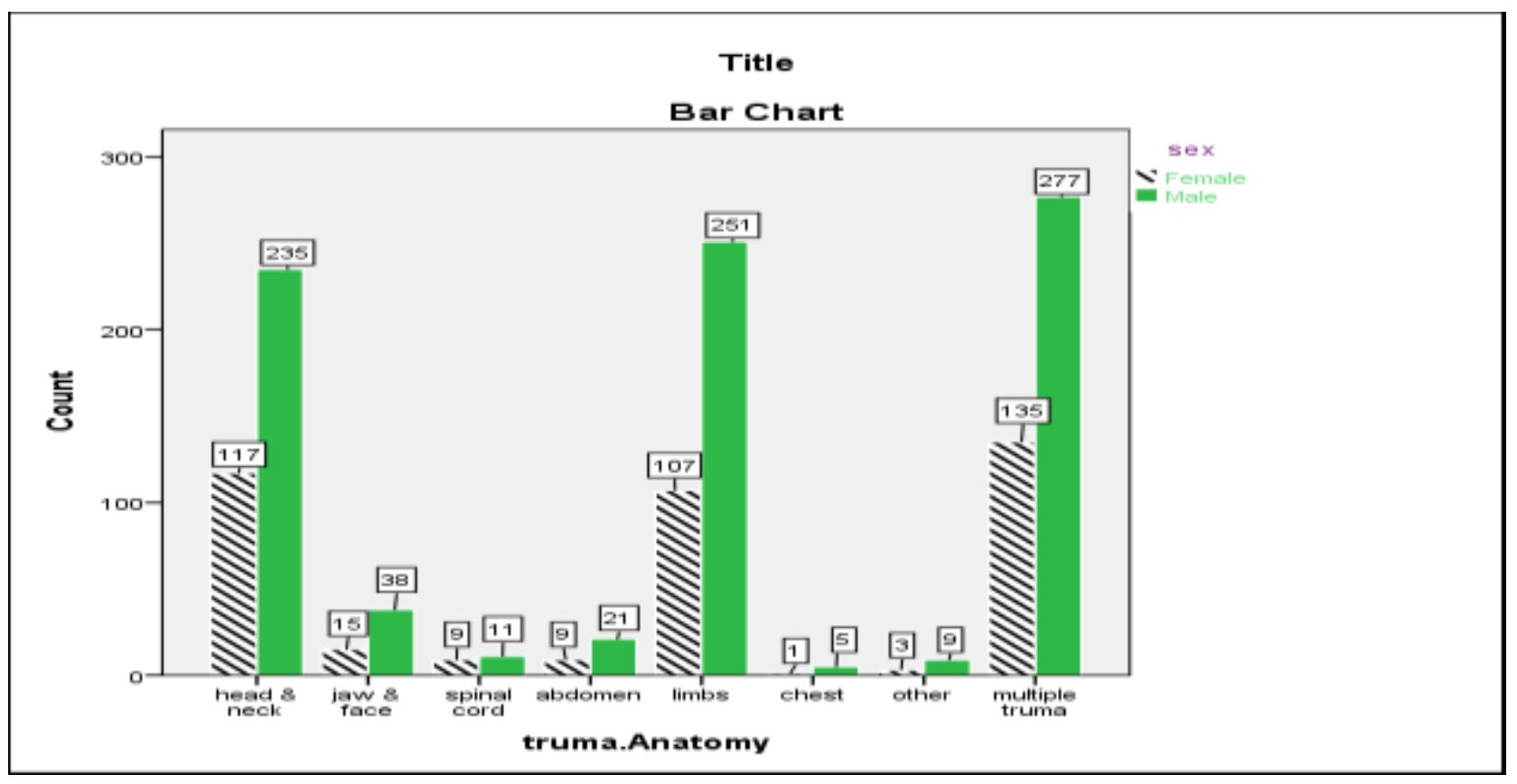

Figure 1. Types of Trauma based on Gender

Among all cases, 1.9 percent of the accidents led to the children's death. The highest frequency was the accidents in the cities with 97.05 percent and the least one was in the villages. The compressions of places in which trauma causes death showed that the highest rate of accidents was in the streets with 62.06 percent in the other places the least one referred to 3.44 percent. The trauma which caused deaths among children, the highest rate was the car accidents with 87.87 percent. The highest rate was among children in winter with 37.5 percent and the least rate was in autumn with 9.37 percent.

\section{Discussion}

Trauma is one of the main factors of mortality rate among the children (Crawford, 1991; McNicholl, 1993; Rutledge, 1993). In the countries like the USA, more than 50 percent of trauma were caused by trauma (Knudson, 1992; Mazurek, 1994). On the other hand, children are more sensitive and susceptible to accidents (Abdoli, 2014). Therefore, the aim of this study was to study the epidemiology of trauma among the children below 15 years old in the ER.

According to the findings of the study, the gender distribution of the patients was matched with the finding of Arhamidolatabadi et al (2016) and Meamarzade et al (2011); however, the rate of the trauma was seen more among males rather than females. This may happen science the types of games are different between girls and boys. The boys are free in their performance but the girls are more limited in their physical and risk taking games.

According to the trauma mechanism statistics, the car accidents and falling down were rated the highest percentage which was the same in the inside and outside the country (Arhamidolatabadi et al, 2016; Meamarzade et al, 2011; Osmond et al, 2002).

Finding showed that trauma incidents happened more in spring and autumn which are in line with Arhamidolatabadi et al (2016), Javid et al (2006), and Meamarzade et al (2011). In the present study, the lowest rate of trauma is in summer since the weather is very hot in summer but the weather is very suitable in spring to play have games (i.e., the weather is hot in 8 months in Khuzestan and it goes up to 60 centigrade in summer days. The highest frequency of body trauma can be seen in multiple trauma, limbs and neck and head. This is matched with Arhamidolatabadi et al (2016), Meamarzade et al (2011), Osmond et al (2002), Kay et al (2006), and Letts et al 2002). This is probably due to the susceptibility of children regarding the trauma of limbs, especially their head which is more frequent than other parts of their body comparing to adults.

The death frequency in children is less than 5 percent which is not matched with Meamarzade et al (2011). There is a meaningful relationship between children's death and the place of the accidents $(p=0.001)$. The records showed that trauma was seen at the highest rate in the streets and 
as the lowest rate at schools. This result is in line with Memarzade et al (2011). This finding may be due to the car accident which causes the severity of accident and the lack secure safety in the cars for children in Iran.

The correlation study showed the death and the type of accident correlated significantly $(p=0.000)$. In other words, the highest rate of trauma was seen in car accidents and the least rate was seen in using toxic materials; however, the relationship between the trauma type and gender was not meaningful $(\mathrm{p}=0.08)$, the anatomical place and gender $(\mathrm{p}=$ 0.78 ), and trauma causing death and the season $(\mathrm{p}=0.1)$ were not meaningful.

The present study faced some limitations like method of study which followed ex-post facto and the problems of cases omitted in data collection procedures.

Since car accidents and falling down were the main cause of trauma. On the other hand, streets and houses were two frequent places of causing trauma. Parents' training and security measures for cars can decrease the rate of trauma among children. It is suggested that similar research on this issue will be conducted in other age ranges in other parts of the country to decrease the rate of trauma in Iranian society

\section{Acknowledgment}

This article was extracted from the research which use issued by the council of research affairs in Medical School of Medical Sciences with Code 95st-0085 and ethical code of IR.ABADANUMS.REC. 1395.130.

\section{References}

1. Abdoli A, Ravari A, Heidari Sh. Study of traumatic accidents the schools of Rafsanjan in 2010 to 2011: A short report. Journal of Rafsanjan University of Medical Sciences 2014; 13(7):642-647.

2. Agran PF, Winn DG, Anderson CL, Del Valle C. Family, social, and cultural factors in pedestrian injuries among Hispanic children. Injury Prevention 1998; 4(3):188-93.

3. Amani F, HabibzadehSh, Rostam Kh. Epidemiological study of Traumatic Patients Referring to Fatemi Hospital of Ardabil, 20072008. Journal of Ardabil University of Medical Sciences 2009; 9(1):13-22.

4. Arhamidolatabadi A, Ebrahimzadeh N, Amini A, Shojaei M, Amiri M. Epidemiology of upper extremity trauma in patients visiting the emergency department; a brief report. Journal Iranian Emergency Medicine. 2016; 3(1):3439. Arhamidolatabadi A, Mohseninia N, Amiri M, Motamed H, Halimiasl AA. Pediatric trauma patient in Imam Hussein emergency department. Iranian Journal of Emergency Medicine 2016; 3(1):4-8.

5. Avarello JT, Cantor RM, Pediatric majorTrauma; an approach to evaluation and Management. Emerg Med Clin North Am 2007; 25(3): 803-36.

6. Bijani M, Nikrooz L, Naghizadeh MM, Tavakol Z. The incidence of chest trauma in patients refers to Vali-Asr hospital of Fasa: Epidemiology of chest trauma. Journal of Fasa University of Medical Sciences 2013; 3(3):285-288.

7. Cooper A, Barlow B, Discala C, String D, RayK, Mottley L. Efficacy of pediatric trauma care: Results of a population-based study. J Pediatr Surg 1993; 28(3): 299-303.

8. Crawford R. Trauma Adult: Experience in North East Scotland. BJS 1991; 11(1):9-16.

9. Davoodabadi A, Yazdani A, Sayyah M ,Mirzadeh Javaheri M. Trauma epidemiology and its consequences in victims referred to the Kashan trauma center during 2007-2008. Journal of Kashan University of Medical Sciences 2011; 14(5):500-505.

10. Forouzanfar MM, Safari S, Niazazari M, Baratloo A, Hashemi B, Hatamabadi H.R. Clinical decision rule to prevent unnecessary chest X-ray in patients with blunt multiple traumas. Emergency Medicine Australasia. 2014; 26(6):561-6.

11. Haghinejad M, Hadavi M, Esmaeilzadeh Sh. Assessment of Epidemiology of traumatic brain injuries and its consequences in Rafsanjan : A descriptive study. Journal of Community Health 2015; 9(3):37-46.

12. Hassanzadeh M, Frhoudinejad A, Yousefzadeh Sh. Using data mining techniques to extract clinical disorders affecting morality in trauma patients. Journal of Gilan University of Medical Sciences 2015; 24(95):52-62.

13. Javid M, Shahcheraghi Gh, Lahiji F, Ahmadi A, Farhadi A, Akasheh Gh.A. Road Traffic Injuries in Children. Iranian Journal of Orthopedic Surgery 2006; 4(3): 1-6.

14. Kay RM, Skaggs DL. Pediatric Poly trauma management. J PediatrOrthop 2006; 26(2): 268-77.

15. Kiakejori K, Latifi A, Monadi M,Sheikhzadeh M, Khafri S. Evaluation of the frequency and type of damage to the ear, nose and throat in patients referring from forensic medical centers to Ayatollah Rouhani hospital in Babol, Iran in 2012. Journal of Babol University of Medical Sciences 2015; 17(8):68-72.

16. Knudson MM, Shagoury C, Lewis FR. Can Adult surgeon care for injured children? J Trauma 1992; 32(6):729-737. 
17. Letts M, Davidson D, Lapner P. Multiple trauma in children predicting out come and longterm results. Can J Surg2002; 445: 126-31.

18. Mazurek AJ. Epidemiology of pediatric injury. Journal of accident and emergency medicine 1994; 11(1):9-16.

19. Mc Nicholl BP, Fisher RB, Rearaden GH. Transatlantic perspective of trauma systems. BJS 1993; 8(80): 985-987.

20. Meamarzade M, Hosseinpour M ,Sanjari N, Karimi Z.A study of trauma epidemiology in children referred to Isfahan Al-Zahra hospital during 2004-7(Feyz) Journal of Kashan university of medical sciences 2011; 14(5):489-493.

21. Noroozinia R, Ahmadi M, Seidabadi M. Assessing the level of knowledge and clinical skills of medical emergencies students Exposure to trauma. Emergency Medicine Journal.2016; 3(2):73-77.

22. Osmond $\mathrm{MH}$, Brennan-Barnes $\mathrm{M}$, Shephard AL. A 4-year review of severe pediatric trauma in eastern Ontario: A descriptive analysis. Journal of Trauma and Acute Care Surgery. 2002; 52(1):8-12.

23. Rahmani R, Mousavi Tabar SY, Karamali M. Epidemiology of trauma in new soldiers during a military training period in one Sepaah training camp, 2012.Nursing and Physician within War 2013; 19-20:5-8.

24. Ramooz A, Hosseini M, Shams Vahdati S. Epidemiology of head and neck fractures caused by motorcycle accident. Iranian Emergency Medicine Journal 2014; 3:23-27.

25. Rutledge R, Fakhry S, Rutherford E, Muakkassa F, Meyer A. Comparison of APACHE II, Trauma Score, and injury severity score as predictors of outcome in critically injured trauma patients. Am J Surg 1993; 166(3):244-7.

26. Safari S, Baratloo A, Negida AS, Taheri MS, Hashemi B, Selkisari SH. Comparing the Interpretation of Traumatic Chest X-Ray by Emergency Medicine Specialists and Radiologists. Archives of Trauma Research. 2014; 3(4): e22189. 27. Souri H. An epidemiological study of children referred to the hospital in Ahvaz incidents. Medical Scientific Journal 2002; (32): 1-11. 